DOT/FAA/AM-03/13

Office of Aerospace Medicine Washington, DC 20591
Automatic Dependent Surveillance - Broadcast / Cockpit Display of Traffic Information: Pilot Use of the Approach Spacing Application

O. Veronika Prinzo

Civil Aerospace Medical Institute

Federal Aviation Administration

Oklahoma City, OK 73125

Alfred M. Hendrix

HCS Consulting Services

Roswell, NM 88201

October 2003

Final Report

This document is available to the public through the National Technical Information Service, Springfield, Virginia 22161.

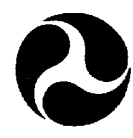

U.S.Department of Transportation

Federal Aviation Administration 


\section{NOTICE}

This document is disseminated under the sponsorship of the U.S. Department of Transportation in the interest of information exchange. The United States Government assumes no liability for the contents thereof. 
Technical Report Documentation Page

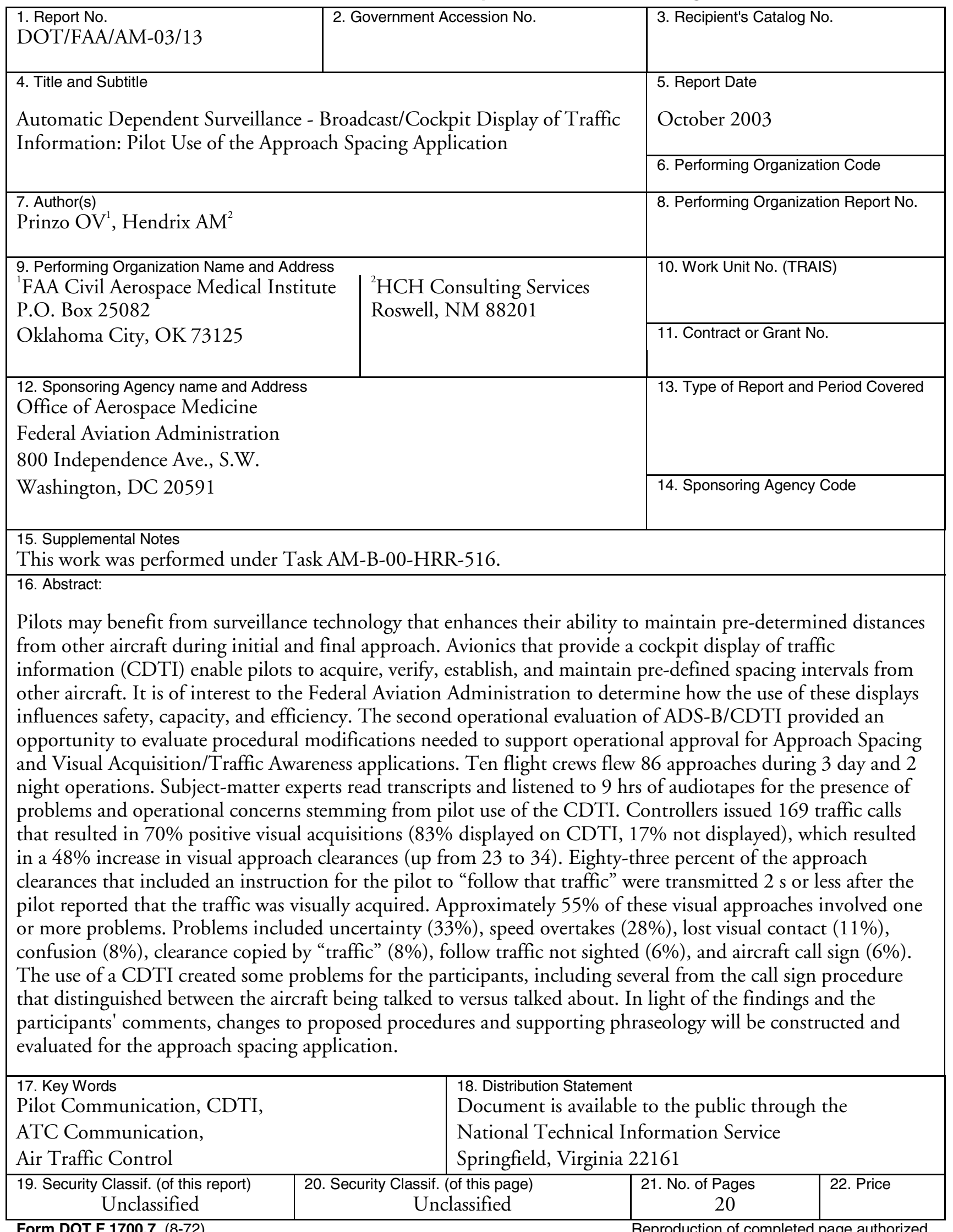

Form DOT F 1700.7 (8-72)

Reproduction of completed page authorized 



\title{
Automatic Dependent Surveillance - Broadcast/Cockpit Display of Traffic Information: Pilot Use of the Approach Spacing Application
}

\author{
Celestial navigation is based on the premise that the Earth is the center of the universe. \\ The premise is wrong, but the navigation works. An incorrect model can be a useful tool.
}

- Kelvin Throop, III

Automatic Dependent Surveillance-Broadcast (ADSB $)^{1}$ is a data link application that will transmit from aircraft and vehicles equipped to emit surveillance data (such as position, type, speed, and identification) by means of a broadcast-mode to users who can receive these data. The Federal Aviation Administration (FAA) anticipates that ADS-B will provide many benefits - from extending the range and coverage of current ground-based secondary surveillance radar (especially in approach areas and on airport surfaces) to increasing air-to-air situational awareness. The FAA envisions that enhanced airborne and ground capabilities would provide for specific surveillance functions that would encourage co-operative air traffic management and collaborative decision-making among its users (Prinzo 2001).

Avionic devices that provide a cockpit display of traffic information (CDTI) capability will enable pilots to acquire, verify, and maintain prescribed spacing minima from other like-equipped ADS-B aircraft. This capability provides pilots with a visual depiction of the current traffic situation with its symbolic display of intent, geometry, and aircraft identity (i.e., traffic flight identifier) information. Instead of relying on communications from air traffic control (ATC) and monitoring the "party line," a CDTI has the potential to enhance, supplement, and project the pilot's mental representation of the traffic situation into the immediate future, using real-time continuous information.

It is of interest to the FAA to determine how the use ofCDTI may influence pilot/controller operational communication and workload. While inclusion of the traffic flight identifier is not part of the standard phraseology, FAA Order 7110.65 does allow for appending additional information to traffic information messages. Using this option permits the evaluation of several communication procedures using the traffic flight identifier as additional information.

\footnotetext{
${ }^{1}$ In 1998, RTCA SC-186 completed Minimum Aviation System Performance Standards for ADS-B. In addition to describing ADS-B, this document also provides information on applications that may use ADS-B information.
}

\section{Anticipated Benefits from Pilot Use of a CDTI}

Some of the anticipated near-term benefits from pilot use of a CDTI device include enhanced safety, optimized aircraft performance, and reduced radio frequency congestion. Each potential benefit is described below.

Enhanced Safety. When both the pilot and controller have access to the same information, they share a common understanding of the traffic patterns, obstructions, and situations. This shared mental model will allow them to participate more fully in collaborative decision-making so all aircraft can safely and efficiently traverse the $\mathrm{Na}$ tional Airspace System. As pilots use CDTI to enhance their situational awareness, they will refine their out-thewindow scan to acquire and track traffic-to-avoid and traffic-to-follow using real-time information.

Optimized Aircraft Performance. The use of CDTI is anticipated to enhance the techniques pilots use to aviate and navigate ownship to establish and maintain specified spacing intervals and speed restrictions. In theory then, pilots can improve upon the efficiency and economy of their flights by optimizing the performance of their aircraft. Ideally, improved flight operations and aircraft performance will translate into fuel savings, less wear and tear on engines, and increased profits for commercial aviation.

Reduced Radio Frequency Congestion. Another expected benefit from CDTI is greater accessibility to an often unavailable radio frequency - especially when talking to ATC is time critical. In today's air traffic control system, certified professional controllers provide pilots with traffic position and sequence information (intermittently and when needed) over an assigned radio frequency. Once the CDTI becomes operational, that same information could be displayed in real-time as continuous graphic and text information to pilots who fly ADS-B equipped aircraft. When pilots and controllers have access to the same information they will be able to optimize communication by transmitting fewer messages.

Consider how CDTI might change air-ground communications by comparing the number and types of messages exchanged between a controller and a pilot of an aircraft not equipped with ADS-B/CDTI (Table 1) to those of the same aircraft equipped with ADS-B/CDTI 
Table 1. Hypothetical Air-Ground Communication Using Existing Surveillance Capabilities

\begin{tabular}{|c|c|c|}
\hline Message & Speaker & Message \\
\hline 1 & ATC & $\begin{array}{l}\text { OWNSHIP ONE TWENTY-THREE REDUCE SPEED TO ONE NINER ZERO } \\
\text { FOLLOWING BOEING SEVEN THIRTY-SEVEN TRAFFIC ELEVEN } \\
\text { O'CLOCK SEVEN MILES WESTBOUND AT FOUR THOUSAND REPORT } \\
\text { TRAFFIC IN SIGHT }\end{array}$ \\
\hline 2 & $\mathrm{ABC} 123$ & OWNSHIP ONE TWENTY-THREE ONE-NINETY TRAFFIC IN SIGHT \\
\hline 3 & ATC & $\begin{array}{l}\text { OWNSHIP ONE TWENTY-THREE REDUCE SPEED TO ONE EIGHT ZERO } \\
\text { TURN LEFT HEADING ZERO EIGHT ZERO }\end{array}$ \\
\hline 4 & $\mathrm{ABC} 123$ & ONE EIGHTY AND ZERO EIGHT ZERO ONE TWENTY-THREE \\
\hline 5 & ATC & $\begin{array}{l}\text { OWNSHIP ONE TWENTY-THREE DESCEND AND MAINTAIN FOUR } \\
\text { THOUSAND TURN LEFT HEADING ZERO SIX ZERO DO YOU STILL } \\
\text { HAVE THE SEVEN THIRTY-SEVEN IN SIGHT }\end{array}$ \\
\hline 6 & $\mathrm{ABC} 123$ & $\begin{array}{l}\text { OWNSHIP ONE TWENTY-THREE DOWN TO FOUR ZERO SIX ZERO } \\
\text { TRAFFIC IN SIGHT }\end{array}$ \\
\hline 7 & ATC & $\begin{array}{l}\text { OWNSHIP ONE TWENTY THREE FOLLOW THE BOEING SEVEN THIRTY- } \\
\text { SEVEN CLEARED VISUAL APPROACH RUNWAY THREE FIVE CENTER } \\
\text { MAINTAIN ONE HUNDRED AND SEVENTY KNOTS TO THE MARKER }\end{array}$ \\
\hline 8 & $\mathrm{ABC} 123$ & $\begin{array}{l}\text { OWNSHIP ONE TWENTY-THREE CLEAR THE VISUAL THREE FIVE } \\
\text { CENTER ONE SEVENTY TO THE MARKER }\end{array}$ \\
\hline 9 & ATC & $\begin{array}{l}\text { OWNSHIP ONE TWENTY-THREE CONTACT TOWER ONE TWO SIX POINT } \\
\text { FIVE FIVE }\end{array}$ \\
\hline 10 & $\mathrm{ABC} 123$ & GOING TO TOWER SO LONG \\
\hline
\end{tabular}

Table 2. Hypothetical Communications Using ADS-B/CDTI Enhanced Surveillance Capabilities

\begin{tabular}{|c|c|c|}
\hline Message & Speaker & Message \\
\hline 1 & ATC & $\begin{array}{l}\text { OWNSHIP ONE TWENTY-THREE REDUCE SPEED TO ONE NINER ZERO } \\
\text { FOLLOWING BOEING SEVEN THIRTY SEVEN TRAFFIC ELEVEN } \\
\text { O'CLOCK SEVEN MILES WESTBOUND AT FOUR THOUSAND REPORT } \\
\text { OTHERSHIP FOUR-FIVE-SIX IN SIGHT }\end{array}$ \\
\hline 2 & $\mathrm{ABC} 123$ & $\begin{array}{l}\text { OWNSHIP ONE TWENTY-THREE ONE NINETY OTHERSHIP FOUR-FIVE } \\
\text { SIX IN SIGHT }\end{array}$ \\
\hline$\vdots$ & $\vdots$ & $\vdots$ \\
\hline 7 & ATC & $\begin{array}{l}\text { OWNSHIP ONE TWENTY-THREE FOLLOW OTHERSHIP FOUR-FIVE-SIX } \\
\text { CLEARED VISUAL APPROACH RUNWAY THREE FIVE CENTER } \\
\text { MAINTAIN ONE HUNDRED AND SEVENTY KNOTS TO THE MARKER }\end{array}$ \\
\hline 8 & $\mathrm{ABC} 123$ & $\begin{array}{l}\text { OWNSHIP ONE TWENTY-THREE CLEAR THE VISUAL THREE FIVE } \\
\text { CENTER BEHIND OTHERSHIP FOUR-FIVE- SIX }\end{array}$ \\
\hline 9 & ATC & $\begin{array}{l}\text { OWNSHIP ONE TWENTY-THREE CONTACT TOWER ONE TWO SIX POINT } \\
\text { FIVE FIVE }\end{array}$ \\
\hline 10 & $\mathrm{ABC} 123$ & GOING TO TOWER SO LONG \\
\hline
\end{tabular}


(Table 2). Message 1 is virtually the same in Table 1 and Table 2. In each message, the controller informs the pilot of $A B C 123$ (the message recipient, Ownship) that a Boeing 737 will be the traffic to follow for the approach and to report when it is sighted. The pilot's report (Message 2) differs only in how the traffic is identified - in Table 1 with the word "TRAFFIC" and in Table 2 by name and flight number spoken sequentially, "OTHERSHIP $456 . "$

By using the traffic flight identifier, any potential ambiguity as to the identity of the traffic is removed. The controller can eliminate messages 3 through 6 in Table 1 by instructing the pilot to follow the sighted traffic at a pre-defined spacing interval, as is the case in Table 2 (Message 7). The last message transfers communication to the tower and serves to close the transaction. Notably, more than half the messages presented in Table 1 involve the aircraft-to-be-followed. It is anticipated that as more aircraft are equipped with $\mathrm{ADS}$-B/CDTI, pilots and controllers will transmit fewer traffic- and routerelated messages.

In October 2000, a second operational evaluation (OpEval-2) of the ADS-B and CDTI occurred for which the purposes were to develop and evaluate specific ADS$\mathrm{B}$ applications, evaluate controller use of ADS-B, and demonstrate ADS-B technology. ${ }^{2}$ Under varying weather conditions, traffic patterns, and aircraft sequences (e.g., a Boeing 727 behind a Boeing 757) different spacing intervals might be desirable. The operational evaluation of ADS-B/CDTI provided an opportunity to examine some of these issues.

Specifically, this operational evaluation demonstrated new air- and ground-based capabilities and systems at an FAA-controlled airport tower and terminal radar approach control facility. With that in mind, it is important to note that it was not possible to apply true experimental and control conditions comparable to that of laboratory-based experiments. Likewise, the training that pilots and controllers received was unequal — making it impossible to exercise any statistical control over the data (e.g., treating the number of hours of training as a co-variant).

What the operational evaluation did provide was an opportunity to gather field data that could be used to guide the development of ADS-B applications (e.g., approach spacing, departure spacing/clearance, runway and final approach occupancy awareness, and airport surface situational awareness). During that 5 -day event, objective and subjective data were collected from controllers and pilots, and a comprehensive report of the findings was

${ }^{2}$ Cited in Flight Crew Mission Guide (Operational Evaluation Coordination Group, OCG 2001). prepared by the Operational Evaluation Coordination Group (OCG, 2001). Reported here is a summary of several analyses performed at the Civil Aerospace Medical Institute on the audiotaped communications between pilots flying aircraft equipped with a CDTI device and terminal radar approach controllers who provided them with air traffic services.

The objective of the voice tape analysis was to identify any change in workload, operational communications, or both that may have occurred during the operational evaluation of a variety of CDTI applications (e.g., Airport Surface Situation Awareness, Departure Spacing, Approach Spacing, Final Approach Runway Occupancy Awareness). This report provides a general description of the communication findings for the approach spacing application only.

\section{METHOD}

\section{Participants}

The pilots were paid volunteers that comprised 10 flight crews who received briefings and participated in proficiency training exercises before the evaluation. The three controllers and two coordinators (also volunteers) were on a temporary detail during training and on a regular schedule during the evaluation.

\section{Experimental Protocol}

Before the evaluation, pilots and controllers participated in several simulations conducted at the Integration and Interaction Laboratory (I-Lab) of the MITRE Corporation's Center for Advanced Aviation System Development (CAASD). During these simulations, pilots received instruction on how to respond to various types of ATC messages and listened to a combination of ATC and pseudo-pilot communications over a party line.

Experimental Flights. Pilots performed the approach spacing application with ADS-B information displayed on their CDTI. As shown in Figure 1, the approach profiles were designed to evaluate the ability of flight crews to manage pre-determined spacing intervals between arriving aircraft. The spacing interval decreased as pilots neared the airport. Typically, pilots flew their aircraft along the assigned routes in a pre-determined pattern, received a clearance to land the aircraft, taxied to the active runway and departed again. The sequence of aircraft in the approach pattern varied with each approach. ATC monitored both participating and non-participating aircraft and ensured preservation of standard separation minimums.

The evaluation included the initial (Figure 1, Point 4 to Point 2) and final approach (Figure 1, Point 2 to runway threshold). The initial approach began approximately 20 


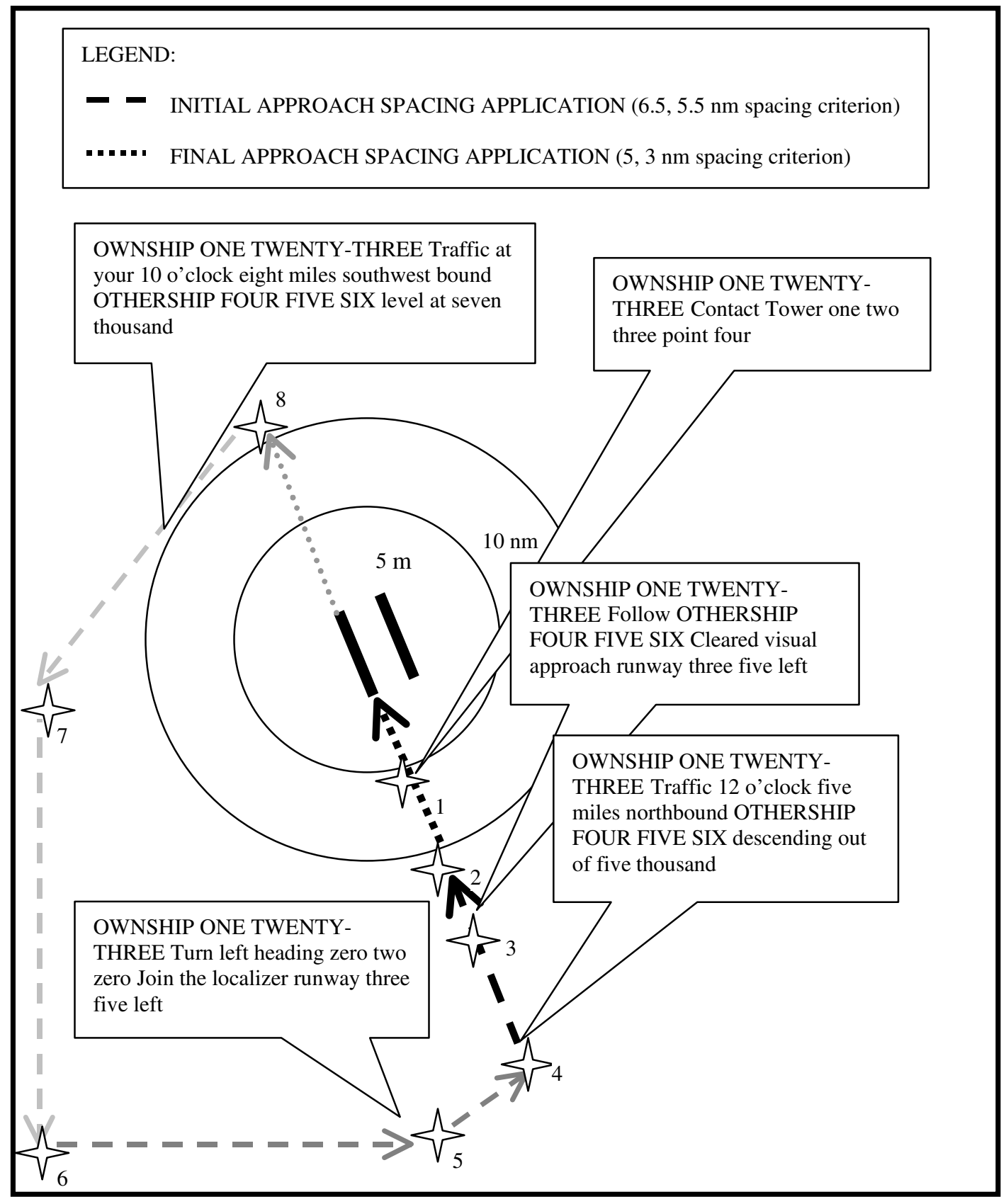

Figure 1. Illustration of the approach spacing application course to runway 35 left.

miles from the runway threshold. During descent, an aircraft on initial approach transitioned from a spacing interval of $6.5 \mathrm{~nm}$ to a final approach spacing interval of $5 \mathrm{~nm}$ (long spacing) and from $5.5 \mathrm{~nm}$ to $3 \mathrm{~nm}$ (short spacing). Final approach began about 10 miles from the runway threshold (Figure 1 Point 2 ). After visually acquiring the traffic to follow (i.e., out the window), the flight crew used the CDTI to reduce the final approach spacing interval to either the long or short spacing criteria by adjusting the aircraft airspeed.

\section{Procedure}

The West portion of the TRACON airspace and the West runway were dedicated to the evaluation activities. In addition, a portion of the airfield was set apart from normal operations with limited access to the West runway for nonparticipating aircraft. This airspace was divided into two sectors using a normal tower position for the West runway. Furthermore, the observations occurred during periods of low traffic volume and when aircraft designated as "heavy" did not require that runway to depart or land. On alternating flight periods the role of pilot in command switched between the captain and first officer. 
During the pre-flight briefings that preceded each data collection activity, all of the participants reviewed the flight scenarios (see Figure 1) and scripts. The facilitators reminded them to follow established procedures and communication protocols (see Table 3). Afterwards, the pilots proceeded to their respective aircraft, and the controllers went to their air traffic control positions. Following each data-collection activity, pilots and controllers participated in post-flight debriefings. Each flight period started and ended at the appointed times.

\section{Materials}

The Terminal Radar Approach Control (TRACON) facility provided five, digital audiotapes (DAT), one for each test period. Each DAT contained separate voice records of all communication transmitted on the radio frequency assigned to the Ground East, Local West, or Approach West position on the left channel. The right channel contained the Universal Time Coordinated (UTC) time code expressed in date, hour (h), minute (min), and whole second (s). The NiceLogger ${ }^{\mathrm{TM}}$ Digital Voice Reproducer System (DVRS) decoded and displayed time and correlated it with the voice stream in real time. The data consisted of 15 hours of digitized voice communications, 9 hours of which were from the Approach West position.

\section{Experimental Design}

This study used a two-factor between-group design. The between group factors were Spacing Interval (Long -6.5 to $5 \mathrm{~nm}$, Short -5.5 to $3 \mathrm{~nm}$ ) and Time of Day (Day, Night). During day operations (Flight Periods 1, $2,4)$, the flight crews completed 24 long and 23 short approaches. For night operations (Flight Periods 3, 5), they completed 20 long and 19 short approaches.

Whether or not an aircraft that was called-out as traffic appeared on the CDTI depended upon the sending and receiving ADS-B links among those aircraft. That is, if Ownship (the receiver of the transmission) only received $1090 \mathrm{MHz}$ and Othership (the aircraft identified as traffic) transmitted on $1090 \mathrm{MHz}$, then its symbol and related information were displayable on the CDTI. If Ownship received $1090 \mathrm{MHz}$ and Othership transmitted on UAT, the data were not displayed. The type of ADS-B equipage (e.g., UAT or $1090 \mathrm{MHz}$ ) was denoted on flight strips that were provided to the controllers. Consequently, Traffic (displayable, not displayable) was included as a factor in some analyses.

\section{Dependent Measures}

The dependent measures included communication workload and operational communications. Measures of communication workload were grouped into efficiency

Table 3. Communication Procedure Developed for Follow a Sighted Aircraft to or on the Approach

\begin{tabular}{|c|c|}
\hline Speaker & Supporting Messages by Flight Profile \\
\hline $\mathrm{ABC} 123$ & $\begin{array}{l}\text { Passing POINT 6, and after slowing: } \\
\text { "ABC 1-23 leaving } 7000 \text { for } 6000 " \\
\text { ATC acknowledges } \\
\text { Approaching POINT } 5\end{array}$ \\
\hline Approach Control & $\begin{array}{l}\text { "ABC 1-23, traffic } 1 \text { o'clock, } 6 \text { miles, } A-B-C-2-3-4 \text { ” } \\
\text { REPLY WITH: }\end{array}$ \\
\hline $\mathrm{ABC} 123$ & $\begin{array}{l}\text { "ABC 1-23, } A-B-C-2-3-4, \text { IN SIGHT" } \\
\text { 'IN SIGHT' Indicates positive Out The Window/CDTI correlation }\end{array}$ \\
\hline Approach Control & "ABC 1-23, follow $A-B-C-2-3-4$, cleared visual approach RWY 35L" \\
\hline $\mathrm{ABC} 123$ & $\begin{array}{l}\text { ABC 1-23 acknowledges, and FLYS THE SPACING TASK } \\
\text { OR: } \\
\text { "ABC 1-23, NOT in sight" } \\
\text { Indicates lack of visual contact, or no Out The Window/CDTI correlation } \\
\text { Expect a later visual acquisition attempt/clearance for the LOC }\end{array}$ \\
\hline Approach Control & "ABC 1-23, traffic 12 o'clock, 6 miles, $A-B-C-2-3-4 "$ \\
\hline
\end{tabular}


and duration of communications. Measures of operational communication included usage of the traffic-flight identifier phraseology, communication problems, and operational concerns.

To measure changes in communication workload and operational communication (the primary variables of interest) for each approach, messages between the controller working approach control and the pilot of each aircraft were grouped into communication sets. A communication set is comprised of messages that share a common goal or purpose that are transmitted between a controller and pilot (Prinzo 1996).

To illustrate, consider the partially encoded transcript presented in Figure 2. Approach \#2 is comprised of messages 1, 2, 3, and messages 8 through 12 and Approach $\# 1$ includes messages 4 through 7 . Four communication sets are associated with Approach \#2. They involve messages transmitted to: (1) establish initial contact, (2) issue and complete a traffic advisory (VAT Comm. Set), (3) instruct the pilot to follow sighted traffic for an approach (IRP-F Comm. Set), and (4) transfer communications to the tower controller.

Objective Measures of Communication Workload. Seven measures of communication workload were examined. The first three dependent measures involved efficiency of communications while the last four dependent measures comprised duration of communications. Efficiency of communications included (1) number of messages transmitted, (2) time on frequency (per message), and (3) frequency occupancy time. Duration of communications involved reply time latencies for: (4) Visual Acquisition Time (VAT), (5) Visual-Acquisition Time-Total (VAT-T), (6) Instruction Route-Position-Follow (IRP-F), and (7) Transaction Set Time (TST). They are described below.

Number ofMessages: The number of pilot and controller messages was counted and aggregated according to the type of analysis that was performed. As seen in Figure 2 , Approach \#2 is comprised of eight messages of which the first two involved initial contact, the next four were traffic related, and the last two focused on transfer of communications. The pilot transmitted two of the traffic-related messages, and the controller transmitted the remainder.

Time on Frequency (TOF): TOF (a) was measured from the onset to offset of individual transmissions, and it represented the amount of time the radio frequency was in use per message. As shown in the example in Figure 2, TOF for the first message was $2 \mathrm{~s}$.

Frequency Occupancy Time (FOT): FOT was computed for each approach by summing the time on frequency for each message. For example, FOT for Approach 2 was 20
$s[\mathrm{FOT}=\Sigma(\mathrm{M} 1+\mathrm{M} 2+\mathrm{M} 3+\mathrm{M} 8+\mathrm{M} 9+\mathrm{M} 10+\mathrm{M} 11+\mathrm{M} 12)$ $=\Sigma(2+1+5+3+4+2+2+1)]$. FOT for the Traffic Information communication set (TI comm. set) was $14 \mathrm{~s}[\Sigma$ $(\mathrm{M} 3+\mathrm{M} 8+\mathrm{M} 9+\mathrm{M} 10)=\Sigma(5+3+4+2)]$.

Latencies were computed for each communication set for approaches that began with initial contact and ended in transfer of communication to the tower controller. An example of how each was computed is presented in Figure 2. These measures were designed to provide a metric to help estimate the operational impact and the benefits of CDTI.

VisualAcquisition Time (VAT): VAT (b) was measured from the offset of the controller's first issuance of a message with traffic-related content to the onset of the pilot's reply, indicating a positive outcome (e.g., traffic in sight, tally ho). The thicker dashed-line illustrates the computation of a VAT of 39 s. VAT began at the completion of message 1 at $788 s$ and ended at $827 \mathrm{~s}$ (message 6) when the pilot of $A B C 123$ informed the controller that the target traffic (ABC4 56 ) was sighted out the window.

Visual Acquisition Time-Total (VAT-T): VAT-T (c) was measured from the onset of the controller's first message that contained traffic-related information (message 1) to the offset of the pilot's final response to that traffic call (message 9). As shown by the thicker solid line, $47 \mathrm{~s}$ lapsed from the onset of the ATC traffic communication at $783 \mathrm{~s}$ to its offset at $830 \mathrm{~s}$.

Instruction Route/Position - Follow time (IRP-F): The thin dashed line shows that IRP-F time (d) was measured from the offset of a traffic advisory (message 1) to onset of the controller's message instructing the pilot to follow traffic (message 10). Upon hearing the pilot's sighting report (message 9) at $830 \mathrm{~s}, 1 \mathrm{~s}$ later the controller instructed the pilot to follow that traffic and issued an approach clearance (message 10). Consequently, $43 \mathrm{~s}$ lapsed from the offset of a traffic call-out to the onset of an instruction to follow traffic.

Transaction Set Time (TST):TST (e) was measured from the onset of the first ATC message in the transactional communication set that contained traffic information to the offset of the final message in that set. It included all messages involved in a Traffic Information communication set (TI comm. set). TI comm. sets typically included a traffic advisory and an instruction to follow traffic, coupled with an approach clearance. The thin solid line shows the values used to compute a transaction set time of $54 \mathrm{~s}$. It begins at $783 \mathrm{~s}$ (message 3 ) with the controller's first message indicating traffic and ends at $837 \mathrm{~s}$ (message 10) with the final message from the pilot that closes the transaction.

Changes in Operational Communications. Changes in operational communications were grouped according 


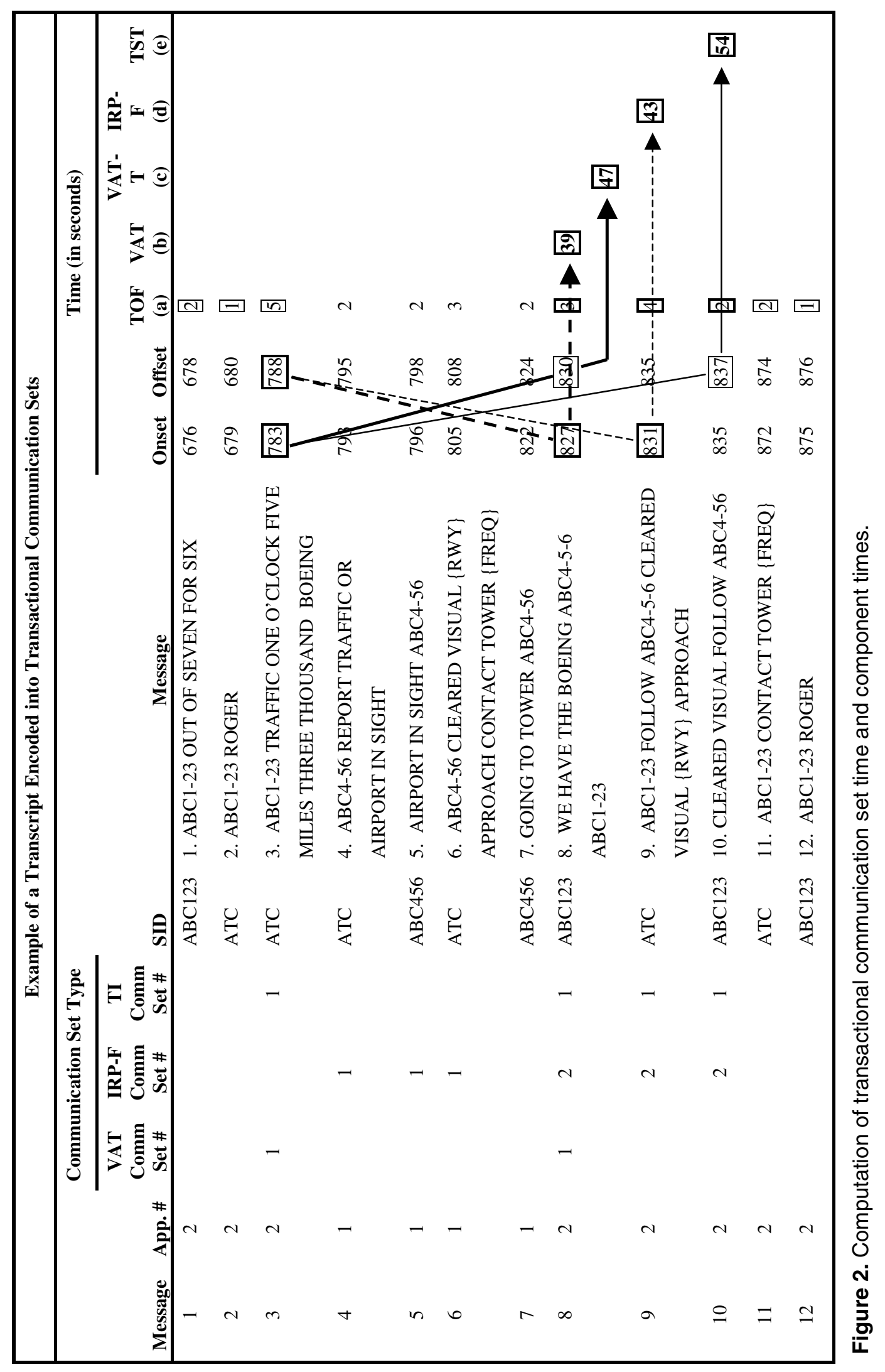


to Traffic Flight Identifier Phraseology Usage, Communication Problems, and Operational Concerns. Each one is described below.

Traffic Flight Identifier Phraseology Usage: The participants in the evaluation had not previously used the traffic flight identifier (TFID) as a routine part of their traffic information messages. Although inclusion of the TFID should clarify communications, its presence might unknowingly change the normal exchange of information flow. Consequently, participants were encouraged to include the TFID if the intruder could be displayed on Ownship's CDTI.

To distinguish between an aircraft being spoken to (Ownship) from an aircraft being spoken about (Othership) in a traffic call, the ICAO phonetic pronunciation of the English alphabet was retained (e.g., Ownship - NOVEMBER ONE NINER ALFA BRAVO). When an aircraft was designated as traffic (i.e., spoken about) and it could be symbolically represented on the CDTI, its flight identifier was to be spoken using conventionally spoken English alphabet letters (e.g., Othership - 'N' One Niner 'A' 'B'). Presented in Figure 3 is a list of TFID usage categories and examples of each.

Communication Problems: Given the newness of using the traffic-flight identifier as a message element in a trafficrelated message, new communication problems may have emerged. Specifically, a communication problem refers to "any disturbance of routine communication, where controllers and pilots do not follow standard procedures, and/or where they must interrupt information transfer in order to clarify the communication" (Morrow, Lee, \& Rodvold, 1990, pp. 36). Communication problems involved the misidentification of target aircraft, confusions, uncertainty, and other disruptions to normal information flow as noted by the SMEs.

Operational Concerns: Operational concerns were identified and categorized according to Traffic Advisory, Position Operation, or both. For example, when pilots reported traffic on the CDTI but not out the window, the occurrence was reported as a concern since pilots were not maintaining compliance with traffic advisory procedures. Also, when pilots lost visual contact with traffic while maintaining self-separation from that traffic, the occurrence was encoded as a concern in flight deck operations.

In summary, message counts, contents, duration, rates, and reply latencies were the objectively derived measures of workload and communication extracted from the time-stamped voice tapes. They were used to compute descriptive statistics expressed as means (M) and standard deviations (SD) that summarized the use of the CDTI by the flight crews who participated in the 5-day evaluation of ADS-B/CDTI applications. Operational communication in the form of traffic flight identifier phraseology, communication problems, and operational concerns provided some insights and implications for future air traffic operations and communications procedures.

Full call sign

Conventionally spoken English alphabet:

... A B C ONE TWO THREE

ICAO phonetic pronunciation

of the English alphabet:

... NOVEMBER ONE TWO THREE GOLF UNIFORM

Standard:

... CESSNA ONE EIGHTY-TWO, HELICOPTER

Partial call sign:

... ONE EIGHTY-TWO, ONE-EIGHT-TWO, HEAVY

Aircraft type/Company/VFR:

... MD-EIGHTY, COMPANY TRAFFIC, VFR TRAFFIC

Implied, but missing:

... FOLLOW AND CLEARED, NOT IN SIGHT

Pronoun:

... HIM or THEM

Traffic:

... TRAFFIC

Figure 3. Traffic Flight Identifier usage categories. 


\section{Data Extraction, Training, and Data Encoding Procedures}

This section begins with a description of the qualifications of the Subject Matter Experts (SMEs), continues with the data extraction procedures and is followed by the procedures used by the lead SME to train the other SMEs. The section ends with an explanation of the data encoding process.

Qualifications of the Subject Matter Experts. The lead air traffic SME was an instrument-rated pilot, as well as a former controller, FAA supervisor/manager (12 years), and FAA Academy instructor (8 years). Two additional SMEs were air traffic instructors (Terminal Option) at the FAA Academy in Oklahoma City. The pilot SME was a recently retired airline pilot with 31 years of experience. Prior to serving as an SME, the pilot's duties included serving as an instructor on the B-727 and DC-8 aircraft; check airman on the DC-9 aircraft; amd pilot of the CV-880, DC-8, B-727, DC-9, L-1011, B-757, and B-767 aircraft.

Data Extraction Procedures. Five sets of audiocassette tapes were dubbed from each digital audio tape (DAT). The transcribers used one copy to generate five sets of verbatim transcripts, and each message was typed onto an electronic copy of the Aviation Topics Speech Acts Taxonomy-Coding Form (ATSAT-CF; Prinzo, Britton, \& Hendrix, 1995). Each message was preceded by its onset and offset time represented in hour $(\mathrm{HH})$ minute (MM) and seconds (SS) and was followed by a column to record comments and a column to code operational concerns.

Training Subject Matter Experts on the ATSAT. The Lead SME provided the other SMEs with 16 hours of training on the data encoding process to achieve consistency and conformity in identifying communication transactions and evaluating the accuracy of content. They evaluated controller/pilot communications effectiveness, identified pilot misunderstandings that pertained to the presence of the TFID, and any repeat of the TFID by the controller. Furthermore, they were to comment on any situation of separation, awareness, and misunderstandings that could be derived from the transcriptions, (e.g., missed readback of the identifiers, routes, and altitudes). Finally, all SMEs were to record any benefits that may have occurred from the pilots having access to a CDTI.

Data Encoding. Each SME received a complete set of audiocassettes, transcripts, and the code and instructional manual. The audiotapes and transcripts aided the SMEs in the identification of communication sets. SMEs worked independently to identify and code the efficiency and accuracy of communications as they related to a traffic advisory, report traffic in sight, advise traffic to follow, report the traffic to follow, follow the correct traffic, and call sign usage. They met on a weekly basis to compare, discuss, and resolve any inconsistencies in data encoding. The lead SME chaired the review process. Less than $2 \%$ of the messages contained any encoding discrepancies, and all were resolved by consensus. The data entry clerks received the final copy of the coded data and entered the information into the database for analysis.

\section{Database Construction}

Each traffic-call that was initiated by the controller, including those that referenced 'previously issued traffic,' was assigned a unique communication set identifier. The communication sets were categorized according to whether the aircraft that was designated as traffic (i.e., Othership) could be displayed on the Ownship's CDTI. The display of Othership on Ownship's CDTI depended upon the sending and receiving ADS-B links among those aircraft. That is, if Ownship only received $1090 \mathrm{MHz}$ and the Othership transmitted on $1090 \mathrm{MHz}$, the communication set was coded 'displayed.' Likewise, if Ownship only received UAT and the Othership transmitted on UAT, the communication set was coded 'displayed.' If Ownship only received $1090 \mathrm{MHz}$ and Othership transmitted on UAT then the communication set was coded 'not displayed.'

\section{RESULTS}

Changes in operational communication that may have resulted from ADS-B/CDTI were evaluated from verbatim transcripts and digitized voice recordings provided by the TRACON facility. Although requests were made during the planning of the event that baseline circuits be included during the evaluation, none were conducted. Consequently, comparisons between the routine and communication protocol developed for pilot use during the evaluation could not be performed since the baseline data necessary for comparison were not included as part of the operational evaluation.

The analyses were restricted to 67 approaches (9 Day Long, 23 Day Short, 19 Night Long, 16 Night Short) that included transactions containing traffic information (TI comm. sets). Each completed approach lasted between $251 \mathrm{~s}$ and $618 \mathrm{~s}(\mathrm{M}=425.8 \mathrm{~s}, \mathrm{SD}=104.9 \mathrm{~s})$ during the long spacing interval and from $187 \mathrm{~s}$ to $664 \mathrm{~s}(\mathrm{M}=488.6$ s, SD=99.8 s) during the short spacing interval. The approach phase began with initial contact to approach control (see Figure 1 Point 6) and ended in transfer of communication to the tower.

Nine hundred and twenty-nine (929) messages (pilots $=536$, controllers $=549$ ) were exchanged between pilots and controllers, of which 320 messages (pilots=158, controllers $=162$ ) comprised 169 TI communication sets. 
A frequency analysis, which included a chi-square test, was performed to determine if CDTI aided pilots in visually acquiring aircraft called-out by ATC as traffic. The results revealed that when traffic was displayable on the CDTI, 76\% of the TI communication sets (99/131) resulted in positive sighting reports compared with 53\% $(20 / 38)$ when traffic was not displayable, $\left(\chi^{2}(1)=7.44\right)$. As shown in Table 4, 60 of the 67 approaches were performed with traffic displayable on the CDTI. Following receipt of positive traffic sighting reports from the flight deck, ATC changed 11 previously issued approach clearances from Instrument Landing System (ILS) to visual approach clearances. This, in turn, resulted in a $48 \%$ increase in visual approach clearances - an increase from 23 to 34 visual approach clearances.

Presented in Table 5 are pilots' and controllers' reply onset latencies associated with messages involving trafficinformation and approach clearances. As the mean latencies for visual approach show, $2.4 \mathrm{~s}$ following the offset of a traffic call-out message from ATC, pilots reported traffic in sight (a). Then, $1.5 \mathrm{~s}$ following the receipt of a positive, out-the-window traffic sighting report, the controllers' transmissions included instructions for the pilots to follow that traffic and a visual approach clearance (b). Pilots acknowledged those instructions and clearances $3.1 \mathrm{~s}$ later (c). On average, $12.7 \mathrm{~s}$ lapsed from the onset of traffic-calls until pilots reported that traffic in sight (d). Generally, $12.1 \mathrm{~s}$ lapsed from the onset of the traffic-calls to the onset of the approach clearances (e) with the entire transaction taking $46.4 \mathrm{~s}$ to complete (f). The $1 \mathrm{~s}$ median reply-onset time indicated that controllers and pilots were very prompt in exchanging information with each other.

\section{Communication Workload}

Multivariate Analysis of Variances (MANOVAs) were performed on the measures of communication workload presented in Table 6 and Table 7. Univariate Analysis of Variance (ANOVA) was used to assess the statistically significant findings. The Tukey Honestly Significant Difference (HSD) statistic was performed on statistically significant interactions. An alpha level of .05 was set for all statistical tests.

Efficiency of Communications: A Spacing Interval by Time of Day by Speaker MANOVA was performed on the mean for each communication efficiency measure and is presented in Table 6 (standard deviations are enclosed in parentheses). It revealed statistically significant main effects of Spacing Interval $[\mathrm{F}(3,124)=6.31]$, Time of Day $[F(3,124)=3.17]$, and Speaker $[F(3,124)=73.36]$, in addition to a statistically significant Time of Day by Speaker interaction, $[\mathrm{F}(3,124)=3.10]$.

Subsequent ANOVAs revealed that when pilots flew the long, compared to the short, spacing interval, 1.17 fewer messages were transmitted per approach $[\mathrm{N}$ Messages, $\mathrm{F}(1,126)=5.84]$ : however, those messages took $.35 \mathrm{~s}$ longer to transmit [TOF, $\mathrm{F}(1,126)=13.74]$. Furthermore, individual messages transmitted during the day took.12s longer to transmit than comparable messages transmitted during the night [TOF, $\mathrm{F}(1,126)=5.25]$, and the radio frequency was occupied for five additional seconds $(5$ s) per approach during the day as compared to night operations [FOT, $\mathrm{F}(1,126)=5.98]$.

The difference in radio frequency use is attributable to the controllers, who spent more time on the radio than pilots, both when transmitting individual messages [TOF, $\mathrm{F}(1,126)=223.11]$ and overall [FOT, $\mathrm{F}(1.126)=57.71]$.

Table 4. Types of Approach Clearances Issued by ATC as a Result of Pilot Traffic Sighting Reports

\begin{tabular}{cccccc}
\hline & \multicolumn{3}{c}{ Types of Approach Clearances Issued } & \\
\cline { 2 - 5 } Source & $\begin{array}{c}\text { Change from } \\
\text { Visual } \\
\text { Approach }\end{array}$ & $\begin{array}{c}\text { ILS to Visual } \\
\text { Approach }\end{array}$ & $\begin{array}{c}\text { ILS } \\
\text { Approach }\end{array}$ & $\begin{array}{c}\text { Change from } \\
\text { Visual to ILS } \\
\text { Approach }\end{array}$ & $\begin{array}{c}\text { Approaches } \\
\text { with Traffic } \\
\text { Calls }\end{array}$ \\
\hline $\begin{array}{c}\text { Traffic Displayable } \\
\text { Traffic Sighted }\end{array}$ & 23 & 11 & 10 & 3 & 47 \\
Traffic Not Sighted & 0 & 1 & 11 & 1 & 13 \\
Total & 23 & 12 & 21 & 4 & 60 \\
Traffic Not Displayable & & & & & 4 \\
Traffic Sighted & 2 & 2 & 0 & 0 & 3 \\
Traffic Not Sighted & 0 & 0 & 3 & 0 & 7 \\
Total & 2 & 2 & 3 & 0 & \\
\hline
\end{tabular}


The statistically significant Time of Day by Speaker interaction, $[\mathrm{TOF}, \mathrm{F}(1,126)=4.86]$ revealed that controllers spent more time on frequency (per message) during day as compared to night operations; however, it did not matter to the pilots whether operations were conducted during the day or night — their messages were equally short, especially when compared to those transmitted by the controllers.

Duration of Communication: A Spacing Interval (Long, Short) by Time of Day (Day, Night) by CDTI (traffic displayable, traffic not displayable) MANOVA was performed on how quickly pilots reported traffic in sight (VAT) and the total amount of time spent on a traffic call - from the onset of the traffic call by ATC to the offset of the pilot's sighting report (VAT-T). Presented in Table 7 are the means and standard deviations (in parentheses) derived from the 119 positive sighting reports.

The results from the MANOVA revealed statistically significant effects for Time of Day $[\mathrm{F}(2,111)=6.50)]$ and for the Spacing Interval by Time of Day interaction

Table 5. Pilot and Controller Reply Times and Total Task Time Measures: Positive Sighting Reports

\begin{tabular}{|c|c|c|c|c|c|c|}
\hline \multirow[b]{2}{*}{$\begin{array}{c}\text { Type of Approach } \\
\text { Clearance }\end{array}$} & \multicolumn{3}{|c|}{ Reply Onset Times } & \multicolumn{3}{|c|}{ Total Task Time } \\
\hline & $\begin{array}{c}\text { Pilot Reply } \\
\text { Traffic } \\
\text { Sighted } \\
\text { (a) } \\
\end{array}$ & $\begin{array}{l}\text { Controller- } \\
\text { Follow } \\
\text { Traffic } \\
\text { (b) } \\
\end{array}$ & $\begin{array}{c}\text { Pilot Reply } \\
\text { Follow } \\
\text { Traffic } \\
\text { (c) }\end{array}$ & $\begin{array}{c}\text { AT Set } \\
\text { Time } \\
\text { (d) }\end{array}$ & $\begin{array}{c}\text { Follow } \\
\text { Traffic w - } \\
\text { Approach } \\
\text { (e) }\end{array}$ & $\begin{array}{c}\text { Total Time } \\
\text { (f) }\end{array}$ \\
\hline \multicolumn{7}{|l|}{ Traffic Displayable } \\
\hline \multicolumn{7}{|l|}{ Visual $(n=23)$} \\
\hline Mean & $2.4(3.6)$ & $1.5(1.4)$ & $3.1(6.3)$ & $12.7(6.1)$ & $12.1(7.1)$ & $46.4(64.8)$ \\
\hline Median & 1.0 & 1.0 & 1.0 & 11.0 & 10.0 & 23.0 \\
\hline Min - Max & $0.0-17.0$ & $0.0-6.0$ & $0.0-27.0$ & $8.0-34.0$ & $7.0-39.0$ & $13.0-284.0$ \\
\hline \multicolumn{7}{|c|}{ Change to Visual $(n=11)$} \\
\hline Mean & $21.4(24.4)$ & $6.6(15.4)$ & $1.2(0.9)$ & $32.3(25.5)$ & $9.8(2.2)$ & $52.9(32.6)$ \\
\hline Median & 18.0 & 1.0 & 1.0 & 27.0 & 10.0 & 47.0 \\
\hline Min - Max & $1.0-74.0$ & $0.0-50.0$ & $0.0-3.0$ & $7.0-80.0$ & $6.0-13.0$ & $16.0-102.0$ \\
\hline \multicolumn{7}{|l|}{ ILS $(n=10)$} \\
\hline Mean & $5.3(7.2)$ & - & - & $17.5(13.9)$ & - & $21.2(18.6)$ \\
\hline Median & 2.0 & 一 & 一 & 13.0 & 一 & 15.0 \\
\hline Min - Max & $1.0-23.0$ & - & - & $10.0-56.0$ & - & $10.0-71.0$ \\
\hline \multicolumn{7}{|l|}{ Change to ILS $(n=3)$} \\
\hline Mean & $2.3(2.3)$ & $10.7(16.7)$ & $1.3(0.6)$ & $10.0(3.0)$ & $10.0(1.7)$ & $35.3(21.4)$ \\
\hline Median & 1.0 & 1.0 & 1.0 & 10.0 & 9.0 & 23.0 \\
\hline Min - Max & $1.0-5.0$ & $1.0-30.0$ & $1.0-2.0$ & $7.0-13.0$ & $9.0-12.0$ & $23.0-60.0$ \\
\hline \multicolumn{7}{|c|}{ Traffic NOT Displayable } \\
\hline \multicolumn{7}{|l|}{ Visual $(n=2)$} \\
\hline Mean & $1.5(0.7)$ & - & - & $12.0(5.7)$ & - & $12.0(5.7)$ \\
\hline Median & 1.5 & - & - & 12.0 & - & 12.0 \\
\hline Min - Max & $1.0-2.0$ & - & - & $8.0-16.0$ & - & $8.0-16.0$ \\
\hline \multicolumn{7}{|c|}{ Change to Visual $(n=2)$} \\
\hline Mean & $1.0(1.4)$ & - & - & $12.0(5.7)$ & - & $24.5(12.0)$ \\
\hline Median & 1.0 & - & - & 12.0 & - & 24.5 \\
\hline Min - Max & $0.0-2.0$ & - & - & $8.0-16.0$ & - & $16.0-33.0$ \\
\hline
\end{tabular}


Table 6. Communication Workload - Efficiency of Communications (per approach)

\begin{tabular}{ccccc}
\hline \multicolumn{1}{c}{ Source } & $\begin{array}{c}\text { Number of } \\
\text { Messages }\end{array}$ & $\begin{array}{c}\text { Time on Frequency } \\
\text { per Message }\end{array}$ & $\begin{array}{c}\text { Frequency } \\
\text { Occupancy Time }\end{array}$ & $\begin{array}{c}\text { Number of } \\
\text { Approaches }\end{array}$ \\
\hline ATC & & & & \\
Day Long Spacing (DL) & $6.11(1.45)$ & $4.86(.77)$ & $30.11(10.52)$ & 9 \\
Day Short Spacing (DS) & $8.04(2.71)$ & $4.16(.83)$ & $33.26(12.55)$ & 23 \\
Night Long Spacing (NL) & $6.42(2.54)$ & $4.07(.70)$ & $25.95(10.52)$ & 19 \\
Night Short Spacing (NS) & $6.81(1.97)$ & $3.88(.89)$ & $26.25(8.69)$ & 16 \\
Flight Deck & & & & $18.22(5.29)$ \\
Day Long Spacing (DL) & $6.67(2.00)$ & $2.75(.40)$ & $17.39(6.46)$ & 23 \\
Day Short Spacing (DS) & $7.91(2.91)$ & $2.22(.41)$ & $15.79(5.56)$ & 19 \\
Night Long Spacing (NL) & $5.95(1.72)$ & $2.64(.38)$ & $15.25(5.83)$ & 16 \\
Night Short Spacing (NS) & $6.44(1.55)$ & $2.31(.49)$ & & 9 \\
\hline
\end{tabular}

Table 7. Communication Workload - Measures of Communication Duration

\begin{tabular}{ccccc}
\hline Source & $\begin{array}{c}\text { Number of } \\
\text { Messages }\end{array}$ & $\begin{array}{c}\text { Visual Acquisition } \\
\text { Time (VAT) }\end{array}$ & $\begin{array}{c}\text { Total Visual } \\
\text { Acquisition Time }\end{array}$ & $\begin{array}{c}\text { Number of } \\
\text { TI Sets }\end{array}$ \\
\hline Traffic Displayable (n=99) & & & & \\
Day Long Spacing (DL) & $4.67(2.08)$ & $32.67(37.45)$ & $54.33(39.53)$ & 3 \\
Day Short Spacing (DS) & $3.51(1.64)$ & $14.92(27.10)$ & $23.92(27.59)$ & 39 \\
Night Long Spacing (NL) & $3.54(1.79)$ & $5.83(10.18)$ & $15.20(11.12)$ & 35 \\
Night Short Spacing (NS) & $3.09(1.41)$ & $5.14(8.29)$ & $15.45(8.48)$ & 22 \\
Traffic Not Displayable (n=20) & & - & & 0 \\
Day Long Spacing (DL) & - & $18.00(16.61)$ & $30.67(15.56)$ & 6 \\
Day Short Spacing (DS) & $4.50(1.38)$ & $5.33(7.15)$ & $13.67(6.84)$ & 12 \\
Night Long Spacing (NL) & $2.67(1.07)$ & $1.50(0.71)$ & $16.00(0.00)$ & 2 \\
Night Short Spacing (NS) & $2.00(0.00)$ & & & 0 \\
\hline
\end{tabular}

$[F(2,111)=16.54]$. Subsequent ANOVAs indicated that pilots were faster to report visually acquiring traffic during the night $(5.41 \mathrm{~s})$ as compared to the day $(16.42$ s) operations [VAT $\mathrm{F}(1,112)=6.62]$, and this effect was found to be independent of the spacing interval they were to maintain. Although it took longer to complete traffic call-outs during the day when pilots were on the long spacing interval $(54.33 \mathrm{~s})$ than during any of the other flights (DS=24.82 s, NL=14.81 s, NS=15.50 s), [VAT-T $\mathrm{F}(1,112)=6.16], p<.05$, this effect was independent of whether traffic was or was not displayable on the CDTI.

Notably, $83 \%$ of the visual approach clearances that included instructions for the pilots to "follow that traffic" were transmitted in $1 \mathrm{~s}$ or less after pilots reported visual contact with that traffic. Likewise, pilots were very prompt in returning receipt - they transmitted $86 \%$ of their acknowledgements in $2 \mathrm{~s}$ or less. Typically, $35 \mathrm{~s}$ or less lapsed from the end of a controller-initiated traffic-call to the start of a visual approach clearance that included the instruction for the pilot to "follow that traffic."

Changes in Operational Communications. There were 301 transmissions included in this set of analyses. The participating controllers and pilots received basic instructions on the call sign procedure prior to the evaluation. The number and types of approaches flown were as follows: 25 visual, 24 ILS, and 18 changed. The changed approaches included: 14 ILS approaches were changed to visual approaches following pilots reporting of 'traffic in sight,' and 4 visual approaches were changed to ILS approaches when pilots reported 'visual contact lost.' 
Traffic Flight Identifier Phraseology Usage: Table 8 shows that when traffic was not displayable on the CDTI, as is the case in today's operations, controllers typically referred to it by aircraft type (e.g., MD-80, Company traffic, Helicopter, VFR) or by the word 'traffic.' In fact, only $2.7 \%$ of their messages included the full traffic flight identifier when that aircraft was not displayable on the CDTI, compared to $87.7 \%$ when it was. This occurred because the controller relied upon flight strip markings for CDTI equipage information and used appropriate phraseology for that traffic pair until informed by the pilot that Ownship's CDTI was not operating properly.
In contrast, pilot usage of the traffic flight identifier was more variable. As shown in the lower half of Table 8 , when traffic was not displayable on the CDTI pilots excluded the traffic flight identifier altogether - more often than not, they responded with the word "traffic." However, when traffic was displayable on the CDTI, more than half of their reports directly referenced that traffic by inclusion of its traffic flight identifier (full $=46.8 \%$, partial $=6.3 \%)$.

A detailed examination of how the traffic flight identifier was spoken is presented in Table 9. It must be pointed out that one controller did not know that one

Table 8. Distribution of the Types of Traffic Flight Identifiers Present in Traffic-Related Messages

Traffic Flight Identifiers

\begin{tabular}{lccccccc}
\multicolumn{1}{c}{ Source } & $\begin{array}{c}\text { Full Call } \\
\text { Sign }\end{array}$ & $\begin{array}{c}\text { Partial } \\
\text { Call Sign }\end{array}$ & $\begin{array}{c}\text { Aircraft } \\
\text { Type }\end{array}$ & 'Traffic' & Pronoun & None & Total N \\
\hline Controllers & & & & & & & \\
$\quad$ Traffic Not Displayable & $2.7 \% *$ & - & $67.6 \%$ & $29.7 \%$ & - & - & 37 \\
$\begin{array}{l}\text { Traffic Displayable } \\
\text { Pilots }\end{array}$ & $87.7 \%$ & $1.6 \%$ & $2.5 \%$ & $8.2 \%$ & - & - & 122 \\
Traffic Not Displayable & - & - & $6.5 \%$ & $48.4 \%$ & $12.9 \%$ & $32.3 \%$ & 31 \\
Traffic Displayable & $46.8 \%$ & $6.3 \%$ & - & $27.9 \%$ & $4.5 \%$ & $14.4 \%$ & 111 \\
\hline
\end{tabular}

* Based on flight strip marking, controller used the full traffic flight identifier until informed by the pilot that the CDTI unit was inoperative.

Table 9. Distribution of the Full and Partial Traffic Flight Identifier Usage by Pilots and Controllers

\begin{tabular}{|c|c|c|c|c|c|c|c|}
\hline \multirow[b]{3}{*}{ Source } & \multicolumn{5}{|c|}{ Full Traffic Flight Identifiers } & \multicolumn{2}{|c|}{$\begin{array}{l}\text { Partial Traffic } \\
\text { Flight Identifiers }\end{array}$} \\
\hline & \multicolumn{2}{|c|}{$\begin{array}{c}\text { ICAO Phonetic } \\
\text { Alphabet }\end{array}$} & \multicolumn{2}{|c|}{$\begin{array}{c}\text { Standard English } \\
\text { Alphabet }\end{array}$} & \multirow{2}{*}{$\begin{array}{c}\text { In Use } \\
\text { Today } \\
\\
\text { Type - } \\
\text { Number } \\
\end{array}$} & \multicolumn{2}{|c|}{ In Use Today } \\
\hline & $\begin{array}{c}\text { Grouped } \\
\text { Numbers } \\
\end{array}$ & $\begin{array}{c}\text { Serial } \\
\text { Numbers } \\
\end{array}$ & $\begin{array}{l}\text { Grouped } \\
\text { Numbers } \\
\end{array}$ & $\begin{array}{c}\text { Serial } \\
\text { Numbers } \\
\end{array}$ & & $\begin{array}{c}\text { Name } \\
\text { Only } \\
\end{array}$ & $\begin{array}{c}\text { Numbers } \\
\text { Only }\end{array}$ \\
\hline \multicolumn{8}{|l|}{ Controllers $(n=110)$} \\
\hline Traffic Not Displayable & - & - & - & $*$ & - & - & - \\
\hline Traffic Displayable & $3.7 \%$ & $3.7 \%$ & & $90.8 \%$ & $.9 \%$ & & $.9 \%$ \\
\hline \multicolumn{8}{|l|}{ Pilots $(n=59)$} \\
\hline Traffic Not Displayable & - & - & - & - & - & - & - \\
\hline Traffic Displayable & - & - & $3.4 \%$ & $72.9 \%$ & $8.5 \%$ & $3.4 \%$ & $8.5 \%$ \\
\hline
\end{tabular}


of the participating aircraft was operating without the capability to display traffic information. The data in the upper portion of Table 9 indicate there was a tendency among the controllers to speak the traffic flight identifier using the conventional English alphabet with the flight numbers spoken sequentially (e.g., A-B-C-1-2-3, not A-B-C-1-23) based on the information provided to the controller. Consequently, controllers communicated with pilots as though their CDTIs were operational (based on flight strip markings) unless told otherwise by the pilots. Rarely did the controllers use the ICAO Phonetic Alphabet (e.g., Alfa-Bravo-Charlie-One-Two-Three or Alfa-BravoCharlie-One-Twenty-three) when referring to traffic. An examination of the transcripts revealed that the ICAO Phonetic Alphabet was spoken primarily during the first day when controllers were first applying the call sign procedure developed for the Operational Evaluation.

The data in the lower half of Table 9 show that pilots did not use the traffic's flight identifier if it was nondisplayable on the CDTI. However, if the traffic's flight identifier could be displayed, there was a tendency to speak it using the conventional English alphabet with flight numbers spoken sequentially (e.g., L-L-L-3, R$\mathrm{K}-\mathrm{W}-9)$. In some cases, pilots reverted to calling the traffic by its conventional name, spoken either with or without its flight numbers (e.g., Lanza Three, Rockwell, Five-oh-Five).

Communication Problems: Eight communication problems involved the misidentification of target aircraft, confusions, uncertainty, and other disruptions to normal information flow. Transmissions such as "Ownship, did you copy traffic?" and "Ownship, that was for an aircraft following you sir" are two examples of communication problems identified from the transcripts. Communication problems and their frequency of occurrence during the approach spacing application are presented in Table 10.

Operational Concerns: Operational Concerns were identified and categorized as concerns related to Traffic Advisory, Position Operation, or both. For example, there were three transactions in which the controller wanted the pilot to verify the identity of the traffic - "Verify it's one two three that Ownship has." As shown in Table 11 , an operational concern for controllers involved an aircraft overtaking the aircraft that it was following for the approach — "Ownship, traffic you're following now four miles ahead currently showing six zero knots faster than that traffic." For pilots who were instructed to maintain visual separation from traffic while on final approach, controllers expressed concerns when pilots reported loss of visual contact with that traffic during the approach. The presence of an aircraft other than Ownship executing a clearance issued to another aircraft resulted only when traffic was displayable on the CDTI. This is best exemplified in the following ATC transmission: "Ownship, roger, that was not for you - follow Othership cleared visual approach runway three five left." The controller action in these cases is no different than today's traffic environment when one aircraft takes a clearance or information intended for another.

\section{DISCUSSION}

The analysis of voice communications from the approach spacing application suggests that neither the pilots who used the ADS-B/CDTI nor the controllers who applied current ATC procedures without the benefit of ADS-B displays experienced notable increases in communication workload. In particular, neither the number nor

Table 10. Distribution of the Various Types of Identified Communication Problems From Transcripts

\begin{tabular}{|c|c|c|c|c|c|c|}
\hline \multirow[b]{2}{*}{ Source } & \multicolumn{5}{|c|}{ Communication Problems } & \multirow[b]{2}{*}{ Total } \\
\hline & Say Again & Correction & $\begin{array}{c}\text { Did You } \\
\text { Copy that } \\
\text { Traffic } \\
\text { Call? }\end{array}$ & $\begin{array}{l}\text { Incorrect } \\
\text { Call Sign } \\
\end{array}$ & Confusion & \\
\hline \multicolumn{7}{|l|}{ Controllers $(n=7)$} \\
\hline Traffic Not Displayable & - & - & $100 \%$ & - & - & 1 \\
\hline Traffic Displayable & - & $16.7 \%$ & $66.7 \%$ & - & $16.7 \%$ & 6 \\
\hline \multicolumn{7}{|l|}{ Pilots $(\mathrm{n}=1)$} \\
\hline Traffic Not Displayable & - & - & - & - & - & 0 \\
\hline Traffic Displayable & $100.0 \%$ & - & - & - & - & 1 \\
\hline
\end{tabular}


Table 11. Distribution of the Various Types of Operational Concerns From Transcripts

\begin{tabular}{|c|c|c|c|c|c|c|}
\hline \multirow[b]{2}{*}{ Source } & \multicolumn{5}{|c|}{ Operational Concerns } & \multirow[b]{2}{*}{ Total } \\
\hline & $\begin{array}{c}\text { Concern } \\
\text { with Speed } \\
\text { Overtake }\end{array}$ & $\begin{array}{c}\text { Pilot } \\
\text { Instructed } \\
\text { to Follow } \\
\text { Traffic } \\
\text { Not } \\
\text { Sighted } \\
\end{array}$ & $\begin{array}{c}\text { Stolen } \\
\text { Clearance }\end{array}$ & $\begin{array}{c}\text { Lost } \\
\text { Visual } \\
\text { Contact } \\
\text { While on } \\
\text { Approach }\end{array}$ & $\begin{array}{c}\text { Equipment } \\
\text { Problem }\end{array}$ & \\
\hline \multicolumn{7}{|l|}{ Controllers $(n=13)$} \\
\hline Traffic Not Displayable & - & - & - & - & - & 0 \\
\hline Traffic Displayable & $76.9 \%$ & $15.4 \%$ & $7.7 \%$ & - & - & 13 \\
\hline \multicolumn{7}{|l|}{ Pilots $(n=7)$} \\
\hline Traffic Not Displayable & - & - & - & $50.0 \%$ & $50.0 \% *$ & 2 \\
\hline Traffic Displayable & - & - & $40.0 \%$ & $60.0 \%$ & - & 5 \\
\hline
\end{tabular}

* An inoperable CDTI resulted in non-displayable traffic onboard one aircraft.

duration of messages resulted in inefficient communications. The discovery of a general trade-off between the number of messages transmitted and duration is typical of day-to-day operational communications. In particular, there were fewer messages of longer duration that were transmitted during the long, compared with the short, spacing interval. Unfortunately, this evaluation did not include conditions that could provide direct comparisons; consequently, a need still exists for research to document the implications of the approach spacing procedure on safety and system efficiency, particularly during periods of heavy traffic capacity.

The results did reveal that, although the presence of a CDTI onboard the aircraft did not produce a statistically significant difference in how quickly pilots reported traffic in sight, it did change the number of actual sightings. That is, when traffic was displayable on the CDTI, $76 \%$ of the traffic calls ended with positive sighting reports compared to $53 \%$ when traffic was not displayable. Upon receipt of positive traffic sighting reports, controllers amended 11 previously issued Instrument Landing System (ILS) approach clearances to visual approach clearances. ${ }^{3}$

A visual approach clearance authorizes the pilot to proceed visually and clear of clouds to the airport. To conduct a visual approach, the pilot must, at all times, have either the airport or the preceding aircraft in sight. This approach must be authorized and under the control of the appropriate air traffic control facility. Reported

${ }^{3}$ The reference for visual approaches and the utilization of them for controllers in covered in FAA Order 7110.65 Chapter 7, Section 4. Pilot's responsibilities for flying visual approaches are best defined in the Aeronautical Information Manual Section 5-4-20. weather at the airport must be ceiling at or above 1,000 feet and visibility of $3 \mathrm{~m}$ or greater. Once the controller issues the visual approach clearance and the pilot accepts it, separation and navigation to the airport become the responsibility of the pilot.

Which type of approach is preferred by pilots - visual or ILS? Performing a visual approach is considered friendlier by pilots than an ILS approach because they can choose the most direct route to touchdown and the spacing behind preceding aircraft. However, many pilots prefer some type of guidance for the approach, rather than a strict visual approach - especially when entering the airspace of a heavily populated airport having a strong presence of commercial aircraft. That is because the more traditional ILS approach brings the aircraft to a specific point approximately $5 \mathrm{~m}$ from the end of the runway, at a specific altitude and speed. Although ILS approaches are less efficient than visual approaches, they serve the purpose of providing pilots exact information as to how they are managing their flight profiles to a specific and safe area on the runway surface. Consequently, pilots might prefer the flexibility of the visual approach, coupled with the precision that is afforded the ILS approach.

The SMEs spent many hours listening to the voice tapes, reading transcripts, encoding communications, and meeting together to discuss their assessments. Their concerns centered on safety. In particular, current air traffic procedures do not allow visual separation by a following aircraft during instrument meteorological conditions. If CDTI electronic flight rules were developed for pilots to use CDTI in lieu of current visual, out-the-window traffic acquisition, separation responsibilities must be clearly understood by both the pilot and air traffic controller. 
For example, during a portion of the operational evaluation, weather conditions became marginal. While the pilot was on approach, visual contact with Othership was lost, whereby the instruction to 'maintain visual separation with that traffic' could no longer be performed. However, the pilot reported, "We lost the visual on the traffic, but we still have them on the CDTI." The example raises the question, "In the event that traffic is no longer visible out the window, but it is displayed on a CDTI, should the pilot be able to continue or relinquish responsibility to ATC?"

If the answer is to continue, then a reexamination will need to be conducted of current procedures and phraseologies that address separation standards, as well as the roles and responsibilities for pilots and controllers for final approach spacing. Specifically, unambiguous procedures and phraseologies must be established to handle normal traffic and occasions when the potential or threat of a loss of minimum separation may occur. This would include the expected/required flight path and separation responsibility during a missed approach or go around. The procedures, separation responsibility, and phraseology must apply during visual or instrument flight rules in visual, marginal visual, or instrument meteorological conditions.

Another important safety issue that was identified by the SMEs involved pilots maintaining specific approach spacing or separation distances and concerns about whether pilots should be permitted to perform CDTI self-spacing, and if so, under what conditions. During the operational evaluation, pilots were working to achieve an assigned spacing interval and often increased their aircraft speed to close the gap between Ownship and Othership. The communications analysis offered some objective support for this concern. There were a number of situations when controllers issued speed advisories from 20 knots up to 70 knots of speed overtake. For example, "Ownship traffic twelve o'clock and three miles Othership you're following is indicating thirty knots slower," or "Othership, previously issued traffic now twelve o'clock and four miles indicating seven zero knots slower."

The voice tape analysis and SME comments further suggested a concern from controllers actively controlling and managing the airspace to only monitoring it when pilots were maintaining their own spacing and speed control - especially under reduced visibility. Should the loss in established minima occur, who would be cited with the infraction - the pilot or the controller? Once again, clearly defined roles and responsibilities for maintaining spacing minima using ADS-B/CDTI under changing visibility and weather conditions must be developed, understood, and agreed upon before the approach spacing procedure is approved.
Finally, an important issue for system developers and system maintainers that must be addressed is the need by ATC for timely updates of airborne CDTI operability. The participating controllers relied upon flight strip markings for CDTI equipage information and used appropriate phraseology for traffic pairs until informed by the pilot that Ownship's CDTI was not operating properly. For example, in response to the ATC message, "Ownship one two three reduce your final approach speed, you are three and a half miles in trail Othership five-sixty doing a hundred and seventeen knots," the flight deck responded with, "Roger, reduce to one one five and our unit is not working so we can't space on him." Will new situation displays automatically provide controllers with an aircraft's ADS-B/CDTI equipage information and update it if the unit is no longer functioning, or will the pilot need to inform the controller upon initial call-up?

Not surprisingly, new research will be needed to determine the effect on the safe, orderly, and expeditious flow of traffic, with the use of pilot-managed approach spacing intervals and any developed CDTI-enhanced flight rules during marginal visibility. If the ADS-B/CDTI approach spacing application is implemented, then a clear understanding is needed of the roles, responsibilities, procedures, and phraseology for pilots and controllers who use it. A vital lesson has been learned from the implementation of a Traffic Collision Avoidance System (TCAS) that applies to ADS-B/CDTI. Any new or modified air traffic procedure that does not include a specific, unambiguous phrase to initiate that procedure contributes to an air traffic incident when not understood by both the pilot and controller.

\section{REFERENCES}

Federal Aviation Administration. (2000). Air Traffic Control (7110.65M). Washington, DC: U.S. Government Printing Office.

Federal Aviation Administration. (2001). Aeronautical Information Manual. Washington, DC: U.S. Government Printing Office.

Joseph, K.M., Domino, D. Battiste, V. and Bone, R. (2003). A Summary of Flightdeck Observer Data from SafeFlight 21 OpEval-2. Federal Aviation Administration, Office of Aerospace Medicine Technical Report DOT/FAA/AM-03/2, Washington, DC.

Minimum Aviation System Performance Standards for Automatic Dependent Surveillance Broadcast (ADS$B)$. Washington DC: RTCA, Inc. (February 1998). (Prepared by SC-186). RTCA/DO-242. 
Morrow, D.G., Lee, A., and Rodvold, M. (1990). Analysis of routine pilot-controller communication. In: Managing the Modern Cockpit: Third Human Error Avoidance Techniques Conference Proceedings. Warrendale PA: Society of Automotive Engineers, Inc.

Operational Evaluation Coordination Group (2001). CAA/FAA/Safeflight21 Operational Evaluation2 Final Report. www.faa.gov/safeflight21/orv/ opeval_2/index.html

Prinzo, O.V. (1996). An Analysis of Approach Control/Pilot Voice Communications. Federal Aviation Administration, Office of Aerospace Medicine Technical Report DOT/FAA/AM-96/26, Washington, DC.
Prinzo, O.V. (2001). Innovations in Pilot Visual Acquisition of Traffic: New Phraseology for Air Traffic Control Operational Communication. Federal Aviation Administration, Office of Aerospace Medicine Technical Report DOT/FAA/AM-01/19, Washington, DC.

Prinzo, O.V., Britton, T.W., and Hendrix, A.M. (1995). Development of a Coding Form for Approach Controll Pilot Voice Communications. Federal Aviation Administration, Office of Aerospace Medicine Technical Report DOT/FAA/AM-95/15, Washington, DC. 
